\title{
DICTIONARIES AND THE INTERPRETATION OF WORDS: A SUMMARY OF DIFFICULTIES
}

\author{
AARON J. RYND*
}

The author explores problems involved in resorting to dictionaries when attempting to define words which may be key to determining a case. He reviews the process lexicographers follow when writing dictionary definitions and concludes that dictionary definitions should be subjected to the same degree of scrutiny as any other evidence. Dictionary meanings are often based on opinions that are not always supportable. The author therefore urges caution when attempting to rely on dictionaries in the courtroom.
L'auteur examine les problèmes que soulève le recours aux dictionnaires dans la définition de termes essentiels à l'arrêt d'une décision. Il passe en revue la démarche qui suivent les lexicographes qui rédigent les dictionnaires et conclut que ces définitions devraient être soumises au même examen rigoureux que toute autre preuve. Les définitions des dictionnaires sont souvent fondées sur des opinions qui ne sont pas toujours défendables. L'auteur invite donc toute personne qui invoque les dictionnaires au tribunal à une certaine mesure de circonspection.

In $R$. v. Arnold ${ }^{1}$ the British Columbia Court of Appeal provided a gloss upon previous judgments interpreting the word "cultivate" in section 6(1) of the Narcotic Control Act, R.S.C. 1985 c. N-1. The decisions in question relied upon the Oxford English Dictionary ("OED"), which ascribes to "cultivate" the meaning "to bestow labour and attention upon (land) in order to the raising [sic] of crops, to till, to improve and render fertile by husbandry".' The Court of Appeal found that this was too narrow and that the OED focused restrictively upon "improving and rendering fertile the land to foster the growing of crops whereas the prohibition encompassed in s. 6(1)... commences when seeding takes place and continues until the marijuana plants are harvested or they die". ${ }^{3}$ The Court was very careful not to purport to enlarge the meaning of the word "cultivate" beyond that given in the OED, but instead addressed itself to the conduct prohibited by the section. The case highlights the problems which may arise when counsel or the Court resort to dictionaries, and this article explores some of those problems.

Lexicography is a scholarly discipline. It proceeds by investigation, analysis, and the construction of theory about words. It is not a science in the usual sense, because lexicography does not progress by the testing of hypotheses. Nor is it an art, because it does not project imagination into external forms. Scholarship in lexicography must be subjected to the same rigours as any other discipline. Its raw material, for example quotations from Charles Dickens, must be studied in context to verify the meaning of the word in question and to confirm the absence of other blunders such as error by Dickens' publisher. This scholarly attitude is essential to the other side of lexicography, namely dictionary compilation. Counsel who refer to a dictionary for the meaning of words assume a great deal about the integrity, scholarship, and even proof-reading which

Barrister and Solicitor, Ph.D. Literature.

Unreported decision, (31 January 1990), No. CA009603.

Ibid. at 5 .

Ibid. at 6-7. 
underlie the dictionary's text. The OED itself contains proof-reading errors, including one in the passage quoted above. ${ }^{4}$

The two general dictionaries which have gained most respect in the English-speaking world are the OED, and Webster's Third International Dictionary ("Webster's"). The 2nd edition of the OED ("OED (2nd)") appeared in 1989; Webster's was published in 1961. The methods and principles of these dictionaries are similar in some respects but significantly different in others. This is true in compilation, method and presentation of material. It is significant to note that there are no uniform rules by which dictionaries operate; counsel looking up "diabolical" in a defamation action may find the most common meaning placed first followed by those meanings less and less often used at the time the dictionary was compiled. Alternatively, meanings may be organized historically, such that the first mentioned occurs rarely today if at all. Both the OED and Webster's employ the latter method.

Sources for the meanings in Webster's or the OED (2nd) are restricted. The OED (2nd) lists meanings only if found in approved written sources. Greatly simplified, the compilation of the OED (2nd) worked something like this. A reader provided the lexicographers with a piece of paper called a "slip" on which was recorded a quotation from an approved text. The lexicographers or their assistants approved and collated the slips, analyzed the usage of words on them and devised descriptions or analyses which became the meanings which found their way onto the dictionary's pages. The pages appeared in volumes over the years as the New English Dictionary on Historical Principles, reissued as the Oxford English Dictionary in August, 1933. The reissued volumes were in due course supplemented, and the OED (2nd) integrates the original and supplemental volumes. ${ }^{5}$ In the case of Webster's, the original collection of words and meanings appeared in Noah Webster's American Dictionary of the English Language (1828). Webster's now is framed upon "new examples of recorded usage" arising from the "systematic reading" of the editorial staff. ${ }^{6}$ Lexicographers take the view that quotations from approved texts represent correct usage and that the dictionary's printed analysis or description corresponds to this usage. From this brief outline, there can be no doubt that dictionaries combine both opinion and hearsay.

Assume that a dictionary's sequence of meanings is intended to reflect the frequency or likelihood of usage in educated speech or print shortly before the dictionary went to press. The choice of sequence constitutes an opinion founded upon facts which are second-hand at best and entirely concealed from Judge and counsel. On this argument, it is probably unwise and perhaps an error for the Court to consult a dictionary without advising counsel first and providing an opportunity for argument as to appropriateness and adequacy of the intended dictionary and rebuttal of any significant printed meaning. If dictionaries are regarded as collections of expert evidence, this caution accords with the practice of taking judicial notice of elementary forensic principles from standard words or periodicals which are "readily and accurately accessible" only after advising counsel

Ibid. at 5; cf. also the OED, 1961 reprint, 1246.

Cf. the OED (2nd) at $x l$ ff.

Webster's at $4 a$. 
that the Court intends to do so. ${ }^{7}$ Dictionaries have been admitted as evidence to establish the ordinary meaning of words and as such they are common-law exceptions to the hearsay rule. ${ }^{8}$ Whether justified in this manner, or considered as refreshing the Judge's memory, ${ }^{9}$ or assisting the Judge's understanding (e.g., of nature), ${ }^{10}$ judicial notice is taken of dictionary meanings which will permit no evidence in rebuttal and which will stand as precedent." Courts have used dictionaries to interpret technical, foreign, statutory, and even legal terms, but are not absolutely safe doing so. ${ }^{12}$ Experts are usually called to explain technical and foreign words. Legal terms are often defined by precedent, and the interpretation of statutory language is a complex subject in itself. If the Court desires to consult a dictionary, however, questions worth posing include which dictionary, and are the dictionary's principles understood?

No dictionary alleges completeness or perfection. The reverse is true. ${ }^{13}$ The volumes of the original OED appeared at various times between 1884 and 1928, and were first supplemented between 1928 and 1933 . The second supplement appeared in four volumes: 1972 (A-G), $1976(\mathrm{H}-\mathrm{N}), 1982$ (O-Scz), and the final volume in 1986. By the time the fourth volume of the 2 nd supplement was published, the earlier three and especially the first two were already out of date. Only 5000 new words and meanings (predominantly in the first third of the alphabet) ${ }^{14}$ found their way into the OED (2nd), and many additional terms had been accumulated or were in the course of compilation when the OED (2nd) appeared in 1989. ${ }^{15}$ These terms are not found in the OED (2nd). The selectivity of Webster' ${ }^{16}$ is even more intense. Such incompleteness or imperfection in the OED (2nd) and Webster's is additional to rapid and possibly ephemeral mutations such as words used by young people or fashionable expressions such as "buzz words". The Court cannot know whether omitted meanings would alter its interpretation of a word. A dictionary may therefore be compared to a witness who provides incomplete, second-hand evidence without the opportunity for cross-examination. It follows that judgments which rely in whole or in part upon a dictionary require careful scrutiny.

Both the OED (2nd) and Webster's rely upon written quotations as evidence for meanings. Both confine themselves to raw material which is in writing. There are, however, differences between written and oral usage. Written meanings may be narrower because written forms cannot compete with the infinite, ever-changing richness of ordinary life whether cultured or not. On the other hand, a poet or novelist may supply ironic depth or insight which extends a word's meaning beyond that customarily assigned to it in common speech. Shakespeare's works contain enhanced language, and jargon

McWilliams, Canadian Criminal Evidence 2nd ed. (Agincourt: Canada Law Book, 1984) at 646. Phipson, Law of Evidence, 13th ed. (London: Sweet \& Maxwell, 1982) at 26; McWilliams, supra, note 7 at 642.

Phipson, supra, note 8 at 2-22.

Cross on Evidence 6th ed. (London: Butterworth, 1985) at 68.

lbid. at 68.

Phipson, supra, note 8 at 26-06.

E.g. OED (2nd) at xi, and xlv for the need for supplementation. Webster's at $4 a$.

OED (2nd) at xii.

OED (2nd) at lv.

"guided by usefulness" (Webster's at 4a). 
exemplifies narrowed usage. The application of a meaning from a dictionary to real life or to facts at a trial cannot be automatic.

If written evidence is inadmissible without proof of its origin and authenticity, counsel and the Court should understand a dictionary's resources and editorial methods before deciding whether to consult it, how to interpret its entries, and what weight to give specific meanings. No statute provides that dictionaries be treated differently from any other material intended to be introduced at trial, and there is no particular reason why dictionaries deserve veneration or special status.

Webster's "basic aim" is to present "current vocabulary", 17 but the earliest historical meaning found by Webster's editors appears at the beginning of each entry. ${ }^{18}$ No dates are given, and it is therefore difficult to ascertain whether unusual circumstances governed any particular usage. Although the OED (2nd) provides quotations and dates, like Webster's it lists earliest meanings first. ${ }^{19}$ Historical usage may or may not assist a Court to interpret statutes of a bygone age; this is a thorny question. But far more problematically, does it help to interpret current utterance or documents?

The OED (2nd)'s goal is to present usage of the English language after 1150 A.D. except for certain scientific or technological fringe vocabulary and other rare exceptions. ${ }^{20}$ The dictionary extends further in science and philosophy than in slang or cant, ${ }^{21}$ and aims to set forth the English language of Great Britain, North America, and other varieties. ${ }^{22}$ Webster's was consulted by the OED (2nd)'s editorial staff.

Webster's, by contrast, starts at 1755 A.D., and selects materials according to its perception of the dictionary's targeted reader. Its "basic aim" is to present the "current vocabulary of standard written and spoken English". ${ }^{23}$ Its selection is "guided by usefulness", and usefulness is "determined by the degree to which terms [are] most likely to be looked for"24 Of neither Webster's nor OED (2nd) can it be said that a contemporary person or legislature must have intended any of the meanings given. If this cannot be affirmed, then it may follow that the linchpin of justification for consulting a dictionary formally or informally in the judicial process can be questioned.

Smaller dictionaries are necessarily less comprehensive in entries than their larger brethren, and may in some cases prefer brevity over clarity in setting out meanings. For purposes of conversation or scrabble, this rarely has serious impact. Such is not true when the course of a civil or criminal trial may be affected. The shorter the dictionary, of course, the more the lexicographer must select and prune. There is great temptation,

Ibid. at 4a, emphasis added.

Ibid. at 4a.

OED (2nd) at $x x i x$.

lbid. at xxii and $\mathrm{xxv}$.

Ibid. at xxv.

Ibid. at xxii.

Webster's at $4 a$, emphasis added.

Ibid. at 4 a. 
for example, to confine the selection in American dictionaries to the most common words and meanings in American contemporary speech. Add words which university students require for term papers, a few business or legal expressions, the mandatory language from Shakespeare (perhaps) and the result is a portable soft-cover dictionary. A project of this kind has merit, but the format requires such concision that many meanings fall by the wayside and those selected to be included are broadly expressed and easily misunderstood. Such a dictionary's accuracy and reliability may be queried. In many cases a reader cannot know what a word means without a preconception of it, and a strengthening of this preconception may often occur in consulting a smaller dictionary, rather than edification.

Lexicographers make subtle choices which determine what appears on the printed page. For example, a character in a novel may describe an experience as "sort of diabolical". The lexicographer chooses between extending the meaning of "diabolical" to include such experience, or interpreting "sort of" as a modifier of "diabolical". In the latter instance, the lexicographer treats the experience as not truly "diabolical". Whether a dictionary chooses the broadening or narrowing approach, and how consistently, is likely impossible to ascertain, and sensible counsel will question the sharpness of focus as well as comprehensiveness of any set of meanings.

Most dictionaries, including Webster's, do not quote passages from which a meaning is elicited. The dictionaries which print a sentence necessarily omit paragraph or context. Counsel is unable to determine whether the usage is ironic, mistaken, or perhaps more intended to link to an antecedent or subsequent element than to stand on its own. Lexicography requires judgment, and in the absence of agreement by trial counsel it may be that such judgments cannot be consulted any more than a Court can privately select and consult its own expert.

Words sometimes are used with clear and distinct meaning, and sometimes not. Some usages are incorrect, and there are degrees and shades of precision ranging from the most predictable usage (jargon) to the most unusual and imaginative (poetry). All may agree that a particular word is employed with certain meanings, but there may be disagreement whether other meanings are merely less common or are wrong. There may also be argument whether a lexicographer's judgment is more worthy of acceptance than that of any other cultivated person.

It is rare for counsel or the Court to consider the editorial policy of a dictionary which is consulted. These policies usually appear in a preface or introduction which, like the health warning on packages of cigarettes, provides a cautionary note to the user. The size of a dictionary in itself does not determine whether it is accurate or appropriate for consultation. Dictionaries are reviewed in the specialist press from time to time, and counsel or the Court may and perhaps should examine critical reviews of a dictionary to which reference has been made.

The nature of language in itself is uncertain, and the reliability and accuracy of dictionaries can rise no higher than the material which is their substance. Words may be compared to archery targets, amoebas, or fog. A lexicographer provides focus on a word as arrows fly to a target, aiming for the bulls-eye of each separate usage. A word may 
have more than one meaning, and a dictionary may satisfactorily express the essence of each of them, but a particular meaning like an archery target may extend beyond its centre. Alternatively, a word may be like an amoeba, in which case it is perfectly clear whether a meaning lies within the definition, but the meanings themselves expand, contract, or change over time; what is accurate one year may not be quite accurate the next. Finally, words may be compared to fog: absolute knowledge of a word's meaning is impossible, just as a careful observer cannot determine exactly where a fog bank starts or stops; yet only exceptionally is it uncertain whether an individual is outside or inside.

In the result, dictionaries may be consulted more for directions of inquiry than for the clear, distinct, and certain meaning of words. Dictionaries in the courtroom should be consulted on notice to counsel and with great care. 